\title{
BOAS PRÁTICAS DA GESTÃO DE RECURSOS HUMANOS PARA MELHOR PRODUTIVIDADE ORGANIZACIONAL
}

\section{ARTIGO ORIGINAL}

ARAÚJO FILHO, Gilberto Carlos De ${ }^{1}$

ARAÚJO FILHO, Gilberto Carlos De. Boas práticas da gestão de recursos humanos para melhor produtividade organizacional. Revista Científica Multidisciplinar Núcleo do Conhecimento. Ano 05, Ed. 11, Vol. 04, pp. 111-122. Novembro de 2020. ISSN: 2448-0959, Link de acesso: https://www.nucleodoconhecimento.com.br/administracao/produtividadeorganizacional

\section{RESUMO}

Este estudo teve o objetivo de analisar as práticas, costumes e políticas organizacionais que induzem à produtividade. A metodologia utilizada foi a pesquisa exploratória tendo como coleta de dados o levantamento bibliográfico. As conclusões mais relevantes são que a produtividade eficaz é induzida pela motivação, fruto de um clima organizacional no qual os colaboradores são entendidos emocionalmente e pessoalmente, pelos gestores organizacionais e pela administração de recursos humanos.

Palavras-chave: Gestão de Pessoas, clima organizacional, motivação, produtividade.

${ }^{1}$ Graduado Em Administração Pela UNIPAC Araguari. Pós-Graduado MBA Em Gestão Da Informação E Do Conhecimento Pela Escola Superior Aberto Do Brasil ESAB. Estudante No Mestrado Internacional Pela Faculdade Integralize. 


\section{INTRODUÇÃO}

O conhecimento tem potencial capaz de mudar um país para melhor. Com as gradativas mudanças ocorridas nas últimas décadas, é primordial profissionais muito bem qualificados, e a informação e busca pelo conhecimento pelos gestores e colaboradores de uma organização é primordial para um bom trabalho produtivo. A gestão eficaz e eficiente de pessoas nas organizações contribui consideravelmente no alcance das metas e objetivos organizacionais.

O desenvolvimento deste trabalho se dá nos fatores pesquisados que se mostraram relevantes na produtividade dos colaboradores nas empresas. São esses os fatores pesquisados: A Administração de Recursos Humanos como colaboradora da produtividade, o clima e a cultura organizacional e por último, de grande importância, a motivação.

Chiavenato (2004) assegura que a Administração de Recursos Humanos (ARH), deve ser melhor chamada de gestão de pessoas, ao invés de meros recursos organizacionais, pois são constituídas por pessoas distintas, dotadas de personalidade própria. São elementos vivos, impulsionadores da organização, capazes de dotá-la de inteligência, capacidade, e são parceiros da organização levando-a a nobreza e ao sucesso.

Através de uma grande curiosidade sobre as práticas aplicadas pelas organizações para incremento da produtividade e satisfação dos colaboradores e as teorias estudadas e fundamentadas por autores e pesquisadores, sentimo-nos estimulados a realizar esta pesquisa.

Portanto a questão a ser investigada neste trabalho é: Quais as principais boas práticas que podem ser promovidas pela gestão de recursos humanos para melhorar a produtividade organizacional? 
Assim, o objetivo geral deste trabalho é avaliar as práticas, costumes e políticas organizacionais que induzem à produtividade. Para isso, faz-se necessário perpassarmos pelos seguintes objetivos secundários:

- Identificar como a Administração de Recursos Humanos (ARH) pode agir como indutora da produtividade;

- Levantar a importância do clima e cultura organizacional e liderança para o desempenho organizacional;

- Mostrar a importância da motivação para a produtividade.

Este trabalho será dividido em três partes. O mesmo foi realizado através de um levantamento bibliográfico em relação as principais obras na área de $\mathrm{RH}$ e gestão de pessoas, artigos e revistas científicos que mencionam o tema e afins deste trabalho de pesquisa. A primeira parte será constituída da importância da Administração de Recursos Humanos (ARH) como desenvolvedora de práticas e políticas de gestão focadas na produtividade. A segunda parte apresenta os estudos sobre como o clima e os comportamentos organizacionais influenciam no desempenho produtivo. A terceira parte mostrará os gatilhos da motivação e como está se relaciona com a produtividade. Para então, finalizarmos o trabalho com as considerações finais.

\section{GESTÃO DE PESSOAS FOCADA NA PRODUTIVIDADE}

A vida das pessoas constitui uma infinidade de intercâmbios com outras pessoas e organizações. O ser humano é eminentemente social e interativo. Não vive solitariamente, mas em constante convivência e relacionamento com seus semelhantes. Devido as suas limitações particulares, os seres humanos são sujeitos a cooperar uns com os outros, formando parceiras para alcançar certos objetivos que a ação pessoal isolada não conseguiria alcançar.

De acordo com Barnard (1971), a organização é um sistema de atividades conscientemente coordenadas de duas ou mais pessoas. A colaboração entre 
pessoas e alcance de objetivos é fundamental para a existência da organização, conforme considera Chiavenato (2004): "uma organização somente existe quando há pessoas capazes de se comunicarem e que estão dispostas a contribuir com ação conjunta, a fim de alcançarem um objetivo comum". (CHIAVENATO, 2004, p.22).

Chiavenato, aponta as contribuições de se estudar Administração de Recursos Humanos para o contexto das organizações:

O estudo das pessoas constitui a unidade básica das organizações e, principalmente, da Administração de Recursos Humanos. Sem organizações e sem pessoas não haveria Administração de Recursos Humanos. A administração de Recursos Humanos tem duas diferentes vertentes de considerar as pessoas: as pessoas como pessoas (dotadas de características próprias de personalidade e individualidade, aspirações, valores, atitudes, motivações e objetivos individuais) e as pessoas como recursos (dotadas de habilidades, capacidades, destrezas e conhecimentos necessários para a tarefa organizacional). (CHIAVENATO, 2004, p.59).

Como as empresas são organizações, e estas compostas por pessoas, estudar Administração de Recursos Humanos é permitir ao administrador desenvolver competências que permitirão não só munir a organização de profissionais qualificados, mas também lidar com conflitos, motivações, entre outros desafios que o gestor deve ser capaz de lidar.

De acordo com Maximiano (2007), a área de Recursos Humanos (RH) deixou de ser simplesmente um departamento pessoal que tinha como principais objetivos: o planejamento de mão-de-obra, recrutamento e seleção de pessoal, treinamento, remuneração, avaliação de desempenho entre outras funções para se tornar um personagem atuante de transformação dentro da organização.

A divisão de Recursos Humanos atuava de forma mecanicista, onde a visão do empregado tendia à obediência e a execução da tarefa, e ao chefe, o controle centralizado. Atualmente este cenário é diferente: os empregados são chamados de colaboradores e os chefes de gestores. 
A função de $\mathrm{RH}$ precisou passar por gradativas transformações, o departamento de recursos humanos surgiu da necessidade de controlar as horas trabalhadas pelos funcionários para efeito de pagamentos e descontos, com o passar dos anos foram atribuídas mais funções, atualmente o contexto é extremamente complexo, com aumento na instabilidade ambiental e a crescente competição entre as organizações a flexibilidade e a agilidade tornam-se fatores imprescindíveis para fazer frente ao processo de mudança que vem ocorrendo, os gestores de recursos humanos precisam dedicar-se menos à administração e mais à estratégia. (STEFANO; IATSKIU; LOPES, 2004. p.2).

Num mundo cada vez mais complicado e extremamente instável, cabe a $\mathrm{RH}$ o papel de servir como meio para condução de transformações a fim de desenvolver uma organização cada vez mais eficaz e efetiva. "[...] as ferramentas para criar organizações competitivas provêm da redefinição e aprimoramento dos Recursos Humanos". (ULRICH, 2001, p.280).

A administração de Recursos Humanos deve munir os colaboradores com boas condições ambientais e organizacionais para que desenvolvam seu trabalho de forma satisfatória, tanto para corporação quanto para o próprio indivíduo. É indispensável remunerar adequadamente, estimular a participação nas decisões da empresa bem como proporcionar programas que incentivem o aprimoramento e o desenvolvimento profissional. (BOHLANDER; SNELL; SHERMAN, 2004)

Para Huselid (1995), as políticas e práticas de $\mathrm{RH}$, têm influência decisiva sobre as habilidades e motivação dos empregados. As habilidades dos empregados são adquiridas nas metodologias de recrutamento e seleção e são transformadas por meio de treinamentos, coaching, mentoria e outros tipos de obras que visam o desenvolvimento. Essas habilidades, no entanto, somente são utilizáveis se essas forem motivadas no desempenho do trabalho. A motivação pode ser ressaltada por meio de práticas que incluem a avaliação individual ou em grupos, a ligação entre performance e as recompensas e a utilização de sistemas de promoção interna que tenham foco no mérito do empregado. Portanto, as práticas de $\mathrm{RH}$ podem influenciar no desempenho da organização. 
A Administração de Recursos Humanos (ARH) consiste no planejamento, organização, desenvolvimento, coordenação e controle de técnicas capazes de gerar o desempenho eficiente do pessoal, ao mesmo tempo em que a organização compõe o meio que permite as pessoas que com ela colaboram a alcançar os objetivos individuais relacionados direta ou indiretamente ao trabalho.

Chiavenato fala sobre os principais objetivos da $\mathrm{ARH}$ :

Criar, manter e desenvolver um contingente de pessoas com habilidades, motivação e satisfação para realizar os objetivos da organização; criar, manter e desenvolver condições organizacionais de aplicação, desenvolvimento e satisfação plena das pessoas, e alcance dos objetivos individuais e alcançar eficiência e eficácia através das pessoas. (CHIAVENATO, 2004, p.138)

Logo, o papel da ARH é fundamentado nos objetivos da empresa, utilizando colaboradores hábeis e competentes para a aplicação efetiva desses objetivos.

Portanto, pela rapidez das inovações tecnológicas e transformações do microambiente e do macroambiente, as organizações devem ser ágeis, inteligentes e competentes. Essas características são repassadas para as organizações, através do conhecimento, trabalho e dedicação dos seus colaboradores.

É imperativo ao profissional de RH ter uma visão integral, ampliada e sistemática acerca do seu trabalho, conforme os autores abaixo discutem:

As atividades exercidas pelo administrador de gestão de pessoas são um conjunto de ações em que cada um acaba afetando as demais, é preciso desenvolver e manter uma base ampla de informações referente ao ambiente interno e externo, utilizando o modelo sistêmico o profissional deve estar atento às interações e influências do ambiente onde está inserido, já que uma atividade praticada em uma área da empresa afeta a empresa como um todo. (STEFANO; IATSKIU; LOPES, 2004, p.4)

O profissional de recursos humanos além de ser graduado em cursos superiores e especializado em recursos humanos deve possuir ou desenvolver um perfil de extraordinária habilidade no tratamento com as pessoas, deve ter visão estratégica,

Disponível em: https://www.nucleodoconhecimento.com.br/administracao/produtividade- 
holística e multidisciplinar. Deve ser um sujeito funcional e provocador das decisões, empreendedor das ações e criador da inovação dentro das organizações. (RIBEIRO, 2005).

As quatro imagens que caracterizam o profissional de $\mathrm{RH}$ são as de parceiro estratégico, especialista administrativo, defensor dos funcionários e agente da mudança. (ULRICH, 2001).

Espera-se que a visão estratégica que, praticamente sempre estiveram restritas à alta direção possam fazer parte do cotidiano de todos os indivíduos na empresa, à medida que se orientem para resultados pretendidos e para tarefas que agreguem valor ao que é produzido. O novo conceito de gestão de pessoas trata-se de uma formulação bastante abrangente, cuja missão é dar nome e identidade ao resultado de um intenso processo de mudança que vem se desenvolvendo nas políticas, nas práticas e nos processos de gestão. (FISCHER, 2002).

Ressalta-se a necessidade do profissional gestor de Recursos Humanos ter uma visão ampla e ser um parceiro acolhedor, comunicativo, interativo e conhecedor das necessidades bilateralmente, ajudando os colaboradores atingirem os objetivos organizacionais e serem valorizados e bem tratados.

\section{CLIMA ORGANIZACIONAL E LIDERANÇA LIGADOS À PRODUTIVIDADE}

Chiavenato (1999) define o clima organizacional como reflexo da interação das pessoas umas com as outras dentro da organização, com os clientes e fornecedores internos e externos, bem como seu grau de satisfação no ambiente e contexto que os rodeia. O clima organizacional pode ser agradável, receptivo, caloroso e envolvente, em um extremo, ou desagradável, agressivo, frio e alienante noutro extremo. A excelência das organizações bem-sucedidas possui o fator humano como responsável pelo sucesso organizacional em plena era da informação. Tendo como 
grande diferencial as vantagens competitivas das empresas obtidas por intermédio das pessoas que nelas trabalham.

Para Bergamini e Coda (1997, p.98), "Clima Organizacional nada mais é do que indicador do nível de satisfação (ou de insatisfação) experimentado pelos empregados no trabalho".

Conforme Gil (2001), os administradores de recursos humanos atuais já não podem mais considerar os empregados como meros recursos da organização ao bel-prazer da mesma. É necessário tratá-los como pessoas que impulsionam a organização investindo nela seu capital humano e tendo o legítimo anseio de retorno de seu investimento.

Luz (2003) conceitua o clima organizacional como sendo impressões gerais ou percepções dos colaboradores com relação ao seu ambiente de trabalho refletindo o comportamento organizacional, que são os atributos específicos de uma organização, seus valores e atitudes que afetam a maneira como as pessoas ou grupos se relacionam no ambiente de trabalho. O clima organizacional está diretamente ligado à maneira como o indivíduo percebe a organização com sua cultura, normas e costumes, como ele interpreta tudo isso e sua reação positiva ou negativa a essa interpretação.

Segundo Moura (2009), para que o clima organizacional seja delineado é necessário que se faça um diagnóstico, observando e avaliando o ambiente a fim de manter ou alterar a conjuntura encontrada realizada pela Gestão de Recursos Humanos. É necessário que os funcionários saibam o que a administração espera que eles produzam, e os administradores precisam saber do que os funcionários precisam para que sejam ambos lados se sintam felizes e realizados.

É necessário que se faça uma avaliação frequente, diagnosticando, observando e avaliando o ambiente organizacional pelos gestores a fim de manter ou alterar sua conjuntura, a fim de proporcionar um ambiente onde haja a satisfação, calor humano e o respeito mútuo. 
A administração deve mostrar claramente os que os funcionários devem fazer pela organização para atingir os objetivos dela e serem recompensados, realizados e satisfeitos por isso.

\section{A IMPORTÂNCIA DA MOTIVAÇÃO NA PRODUTIVIDADE}

De acordo com Maximiano (1995, p.318), "motivação é o conjunto de razões ou motivos que explicam, induzem, incentivam, estimulam ou provocam algum tipo de ação ou comportamento". Entretanto Robbins (2002) define motivação como "o processo responsável pela intensidade, direção e persistência dos esforços de uma pessoa para o alcance de uma determinada meta".

No que diz respeito à objetivos: a definição de motivação vem da vontade de empregar altos níveis de esforços em direção as metas organizacionais, condicionadas pela capacidade de satisfazer alguma necessidade do indivíduo (ROBBINS, 1994).

A motivação impulsiona o coração e a mente das pessoas e isso só é viável quando realizados de forma verdadeira, desta forma existe a teoria e as ações devem ser baseadas nelas. (KONDO, 1991)

São as seguintes teorias da motivação:

a) Teoria das Necessidades de Maslow: o comportamento motivacional é explicado pelas necessidades humanas, a motivação é o resultado dos estímulos que agem sobre os indivíduos, levando-os a ação. Para que haja ação ou reação é preciso que um estímulo seja implementado, seja decorrente do ambiente externo ou proveniente do próprio organismo. Esta teoria possui a ideia de um ciclo, o Ciclo Motivacional (ROBBINS, 2002).

b) Teoria X e Y: McGregor (apud ROBBINS, 2002) propôs duas visões diferentes do indivíduo: uma negativa, chamada Teoria X, e outra positiva, denominada Teoria Y. A teoria $X$ apresenta quatro premissas que de acordo com Mc Gregor (apud ROBBINS, 2002) são: Os funcionários, por natureza não gostam de trabalhar, e sempre que 
possível tentarão evitar trabalhar; e como não gostam de trabalhar, precisam ser coagidos, controlados ou ameaçados para que atinjam as metas; eles evitam responsabilidades e sempre que possível estão em busca de uma orientação formal; e grande parte dos trabalhadores priorizam a segurança em meio aos demais fatores associados ao trabalho e demonstram pouca ambição. Já as premissas positivas, denominadas como Teoria $\mathrm{Y}$ apresentam as seguintes características: Os funcionários acham o trabalho tão natural quanto descansar ou se divertir; as pessoas apresentarão auto orientação e autocontrole se estiverem comprometidas com os objetivos; as pessoas, na média, podem aprender a aceitar e até buscar responsabilidades; e todas elas são capazes de tomar decisões inovadoras, não sendo um privilégio exclusivo de posições hierárquicas mais altas.

c) Teoria de Dois Fatores de Herzberg: Herzberg (apud CASADO, 2002) criou a teoria dos dois fatores explicando o comportamento das pessoas no ambiente de trabalho. Dois fatores orientam o comportamento das pessoas.

- Fatores Higiênicos (extrínsecos): o salário, os benefícios sociais, o tipo de gerência, as condições físicas e ambientais de trabalho.

- Fatores Motivacionais (intrínsecos): estão relacionados com o conteúdo do cargo e com a natureza das tarefas que a pessoa executa.

De acordo com Limongi-França (2003) a produtividade tem sido definida como o aproveitamento máximo dos recursos para produzir bem e serviços. Enquanto Silva (1987, apud LIMONGI-FRANÇA, 2003) estabelece a proporção entre os recursos obtidos.

Carvalho e Serafim (1995) conceituam produtividade no trabalho como um processo que, a partir do potencial do empregado motivado, utiliza o máximo de sua capacidade em um mínimo de tempo e esforço.

Conforme Lucena (2004) o fator humano é decisivo para incentivar os ganhos de produtividade de bens e serviços, é o ser humano, a força responsável pela realização do empreendimento empresarial, considerando as variáveis de força de trabalho: 
mercado, novas aplicações tecnológicas, matéria-prima, mudanças organizacionais, mudanças de cargos novos, abordagem de mercado, facilidades e dificuldades de mão-de-obra, competitividade, escassez de recursos diversos; como quem impõe as iniciativas inovadoras.

A produtividade é a mentalidade do progresso, do aperfeiçoamento constante. É vontade de mudar a situação atual, por melhor que possa parecer, ou seja, na realidade; é um esforço contínuo em aplicar novas técnicas e métodos (CARVALHO; SERAFIM, 1995). A produtividade não deve ser restrita apenas a indústria, pois a produção de trabalho dever ser eficiente e econômica. $\mathrm{O}$ aumento da produtividade significa tornar uma tarefa mais eficiente com menos recursos e aptidões.

Os fatores que contribuem para um efetivo aumento da produtividade no trabalho, por Serafim e Carvalho (1995) são: quantidade e qualidade dos recursos materiais disponíveis, qualidade da mão-de-obra empregada, gestão de trabalho e nível de motivação do empregado. $O$ fator humano não depende de aspectos isolados para êxito do trabalho.

Jean Fourastié (apud CARVALHO E SERAFIM, 1995) afirma que é evidente que tanto o aumento da produtividade como da produção depende da modernização da maquinaria utilizada e do desenvolvimento da tecnologia utilizada. Entretanto, a prioridade na questão está na contribuição do homem - ou no trabalho que sabe como fazer e tem vontade de executar - como o principal e mais importante fator de produtividade. O processo de produtividade e qualidade muda o comportamento dos colaboradores, os problemas em relação à quantidade, prazos e custos de produção ficam em segundo plano.

Segundo Ferreira (2004) para que a produtividade no trabalho seja melhorada é necessário alguns aspectos e costumes: aprender a dizer não; marcar compromissos com data e hora estabelecidos; reservar tempo para saúde, criar condições favoráveis para um bom atendimento telefônico com eficácia e eficiência; utilizar a Internet e o email para facilitar a vida; minimizar as atividades do dia-a-dia que não agregam valor 
a atividade profissional; utilizar programas (softwares) de auxílio ao planejamento de atividades. Esses aspectos mostram que gerenciar o tempo é como gerenciar a própria vida, de extrema importância. Trabalhe o tempo dando o valor que ele tem para a sua vida.

\section{CONSIDERAÇÕES FINAIS}

O profissional gestor de Recursos Humanos ter uma visão ampla e ser um parceiro acolhedor, comunicativo, interativo e conhecedor das necessidades bilateralmente, ajudando os colaboradores atingirem os objetivos organizacionais e serem valorizados e bem tratados.

É de extrema importância que se faça uma avaliação frequente, diagnosticando, observando e avaliando o ambiente organizacional pelos gestores a fim de manter ou alterar sua conjuntura, a fim de proporcionar um ambiente onde haja a satisfação, calor humano e o respeito mútuo.

A administração deve mostrar claramente o que os funcionários devem fazer pela organização para atingir os objetivos dela e serem recompensados, realizados e satisfeitos por isso.

Somos necessariamente sociáveis. Juntos somos mais fortes. Devemos nos entender e entender os outros. O líder, os gestores e colaboradores devem conviver e comunicar eficientemente para o bom desempenho e convívio organizacional focados na produtividade, isso é conseguido através de uma formação sólida dos gestores e do bom senso.

A gestão de pessoas, representada pela gestão de recursos humanos, e as outras lideranças organizacionais, conjuntamente, devem ter por objetivo entender os funcionários (colaboradores), pessoalmente e emocionalmente, para conhecê-los e guiá-los amigavelmente e conjuntamente para os objetivos e metas organizacionais. 
Um ambiente bem organizado, agradável, com condições favoráveis para execução das tarefas e alinhado com boas práticas e estímulos por parte da liderança, através de atitudes exemplares e benefícios para os colabores, os farão sentirem valorizados e apoiados para executarem com excelência suas atribuições e impulsionarem o desenvolvimento organizacional e suas próprias metas pessoais.

Conforme fala Chiavenato (1999), a excelência das organizações bem-sucedidas possui o fator humano como sendo o responsável pelo sucesso empresarial em plena era da informação. O grande diferencial das vantagens competitivas de uma determinada organização vem por intermédio das pessoas que nela trabalham e isso acontece somente se elas estiverem motivadas o suficiente.

\section{REFERÊNCIAS}

BARNARD, C. I. As Funções do Executivo. São Paulo: Atlas, 1971.

BERGAMINI, C. W.; CODA, R. Motivação nas Organizações. 4. ed. São Paulo: Atlas, 1997.

BERGAMINI, C. W.; CODA, R. Psicodinâmica da Vida Organizacional: Motivação e Liderança. 2. ed. São Paulo: Atlas, 1997.

BOHLANDER, G; SNELL, S; SHERMAN, A. Administração de Recursos Humanos. São Paulo: Pioneira Thomson Learning, 2003.

CARVALHO, A. V.; SERAFIM, O. C. G. Administração de Recursos Humanos. 2. ed. São Paulo: Pioneira, 1995.

CHIAVENATO, I. Gestão de Pessoas: O novo papel dos recursos humanos das organizações. 9. ed. Rio de Janeiro: Campus, 1999.

CHIAVENATO, I. Recursos humanos: o capital humano das organizações. 8. ed. São Paulo: Atlas, 2004. 
FERREIRA, G. A. Manual de Gerenciamento e Produtividade do Tempo. Rio de Janeiro: Qualitymark, 2004.

FISCHER, R.M. As pessoas na organização. In: Fleury, M.T.L. (Coord). 2002. 6. ed, São Paulo: Gente, 2002. 18 p.

GIL, A. C. Gestão de Pessoas: Enfoque nos papéis profissionais. São Paulo: Atlas, 2001.

HUSELID, M.A. The impact of human resource management practices on turnover, producity, and corporate financial performance. Academy of Management Journal, Texas, v. 38, p. 635-672, 1995.

KONDO, Y. Motivação Humana. Rio de Janeiro: Gente, 1991.

LIMONGI-FRANÇA, A. C. Qualidade de vida no trabalho. São Paulo: Atlas, 2003.

LUCENA, M. D. Planejamento estratégico e gestão do desempenho para resultados. São Paulo: Atlas, 2004.

LUZ, R. Gestão do Clima Organizacional. Rio de Janeiro: Qualitymark, 2003.

MAXIMIANO, A. C. A. Introdução à administração. 4. ed. São Paulo: Atlas, 1995.

MAXIMIANO, A. C. A. Introdução à administração. 7. ed. São Paulo: Atlas, 2007.

RIBEIRO, A. de L. Gestão de Pessoas. São Paulo: Saraiva, 2005.

ROBBINS, S.P. Comportamento organizacional. 9. ed. São Paulo: Prentice Hall, 2002.

STEFANO, S.R.; IATSKIU, S.; LOPES, E.R. Ensino de Administração de recursos humanos: a visão dos alunos e profissionais da área. In: Seminário de administração, VII. 2009, São Paulo. 
ULRICH, D. Os campeões de Recursos Humanos: Inovando para obter os melhores resultados. 7. ed. São Paulo: Futura, 2001.

VROOM, V.H. Gestão de pessoas não de pessoal. 9. ed. Rio de Janeiro: Campus, 1997.

Enviado: Agosto, 2020.

Aprovado: Novembro, 2020. 